(6) OPEN ACCESS

\title{
Efficacy of novel immunotherapy regimens in patients with metastatic melanoma with germline CDKN2A mutations
}

\author{
Hildur Helgadottir, ${ }^{1}$ Paola Ghiorzo, ${ }^{2}$ Remco van Doorn, ${ }^{3}$ Susana Puig, ${ }^{4,5}$ Max Levin, ${ }^{6}$ \\ Richard Kefford, ${ }^{7}$ Martin Lauss, ${ }^{8}$ Paola Queirolo, ${ }^{9}$ Lorenza Pastorino, ${ }^{2}$ Ellen Kapiteijn, ${ }^{10}$ \\ Miriam Potrony, ${ }^{4,5}$ Cristina Carrera, ${ }^{4,5}$ Håkan Olsson, ${ }^{8}$ Veronica Höiom, ${ }^{1}$ \\ Göran Jönsson ${ }^{8}$
}

For numbered affiliations see end of article.

\section{Correspondence to} Dr Hildur Helgadottir, Department of Oncology and Pathology, Karolinska Institutet and Karolinska University Hospital, Solna 171 76, Stockholm;

Hildur.Helgadottir@karolinska. se

Received 18 July 2018 Revised 23 August 2018 Accepted 11 September 2018

\begin{abstract}
Background Inherited CDKN2A mutation is a strong risk factor for cutaneous melanoma. Moreover, carriers have been found to have poor melanoma-specific survival. In this study, responses to novel immunotherapy agents in CDKN2A mutation carriers with metastatic melanoma were evaluated.

Methods CDKN2A mutation carriers that have developed metastatic melanoma and undergone immunotherapy treatments were identified among carriers enrolled in follow-up studies for familial melanoma. The carriers' responses were compared with responses reported in phase III clinical trials for CTLA-4 and PD-1 inhibitors. From publicly available data sets, melanomas with somatic CDKN2A mutation were analysed for association with tumour mutational load. Results Eleven of 19 carriers (58\%) responded to the therapy, a significantly higher frequency than observed in clinical trials $(p=0.03$, binomial test against an expected rate of $37 \%$ ). Further, 6 of the 19 carriers (32\%) had complete response, a significantly higher frequency than observed in clinical trials $(p=0.01$, binomial test against an expected rate of 7\%). In 118 melanomas with somatic CDKN2A mutations, significantly higher total numbers of mutations were observed compared with 761 melanomas without CDKN2A mutation (Wilcoxon test, $\mathrm{p}<0.001$ ).
\end{abstract}

Conclusion Patients with CDKN2A mutated melanoma may have improved immunotherapy responses due to increased tumour mutational load, resulting in more neoantigens and stronger antitumorous immune responses.

\section{BACKGROUND}

Inherited pathogenic variants in the CDKN2A gene are among the strongest known risk factors for cutaneous melanoma. ${ }^{1}$ CDKN $2 A$ is a tumour suppressor gene on chromosome $9 \mathrm{p} 21$ encoding for the cell cycle inhibitors p16 and p14ARF. Germline CDKN2A mutations are identified in familial melanoma probands but are rare in the normal population $(<0.1 \%) .^{2}$ Mutation carriers have a risk of melanoma that is $>65$-fold increased and a lifetime penetrance for melanoma of $>70 \% .^{1}$ CDKN2A mutation carriers have a high risk of developing multiple primary melanomas and also other cancers. ${ }^{134}$ Additionally, a previous study reported that germline CDKN2A mutation carriers had inferior melanoma-specific survival that was independent of American Joint Committee on Cancer (AJCC) stage, age and sex, and not associated with the diagnosis of subsequent primary melanomas or other cancers. ${ }^{5}$ Somatic CDKN2A mutations and deletions are frequent driver events in melanoma tumours and CDKN2A deletions and loss of p16 protein have been associated with increased tumour proliferation, increased risk of metastases and decreased patient survival. ${ }^{6-10}$ Melanomas are, in general, tumours with very high mutation burden, with frequent ultraviolet light-induced mutations in many genes. ${ }^{11}$ Besides CDKN2A, BRAF and NRAS are the genes that are most frequently mutated in melanoma tumours. ${ }^{67}$

Disseminated melanoma is notoriously difficult to treat with standard chemotherapy agents and there are still no single or combination chemotherapy regimens that have shown to prolong the patient's survival. In recent years, however, effective targeted therapies and immunotherapy regimens, particularly the CTLA-4 and PD-1 blocking antibodies have emerged for the treatment of melanoma. ${ }^{12-15}$ These, so called immune checkpoint inhibitors, act by blocking an innate negative regulation of $\mathrm{T}$ cell activation and response, thus allowing the immune system to attack the tumour. The emergence of these treatments has revolutionised the melanoma oncology field, but unfortunately a considerable fraction of patients with melanoma do not respond to immunotherapies. Immune checkpoint inhibitors are also associated with immune-related side effects that can be serious and life-threatening. ${ }^{12-15}$ For this reason, it is important to increase the knowledge about predictive factors and the efficacy of the therapies in different patient groups. Clinical factors such as poor performance status, multiple sites of metastases and high tumour burden predict inferior responses, as well as when immunotherapies are given after progression on preceding lines of therapies. Yet, the knowledge on other predictive factors for checkpoint inhibitors is limited. Patients with tumours that harbour activating $B R A F$ mutations respond equally to immune checkpoint inhibitors as those without such mutations. ${ }^{13-15}$ However, 
there is growing evidence that tumour mutational burden is a strong independent predictive factor for efficacy of immunotherapies. ${ }^{716-18}$ So far, there have been no studies addressing the effect of immunotherapy regimens in patients with melanoma with germline CDKN2A mutations.

\section{METHODS}

\section{Patient accrual}

CDKN2A mutation carriers that have developed metastatic melanoma and undergone immunotherapy treatments were identified by reviewing medical records of carriers enrolled in follow-up studies for familial melanoma. The different studies in which mutation carriers were identified have previously been described. ${ }^{1-419}$ Data were collected on the type of germline CDKN2A mutation and its effect on p16 and p14ARF, age and sex of the patient, tumour stage (according to the eighth edition of the AJCC cancer staging system, implemented January 2018), BRAF mutation status of tumours, type of immunotherapy, line of treatment, previous therapies, responses, survival and treatment side effects. The carriers received the immune checkpoint inhibitors according to standard dosage and treatment schedules; CTLA.4 blockade: ipilimumab, $3 \mathrm{mg} / \mathrm{kg}$, four courses, every third week or tremelimumab, $15 \mathrm{mg} / \mathrm{kg}$, four courses every 90th day; PD1-blockade: nivolumab, $3 \mathrm{mg} / \mathrm{kg}$ every second week or pembrolizumab, $2 \mathrm{mg} / \mathrm{kg}$, every third week, both drugs as long as tolerated or until progression; CTLA-4/PD-1 blockade: ipilimumab $3 \mathrm{mg} /$ $\mathrm{kg}+$ nivolumab $1 \mathrm{mg} / \mathrm{kg}$, four courses every third week followed by nivolumab $3 \mathrm{mg} / \mathrm{kg}$ every second week as long as tolerated or until progression; PD-1/BRAF/MEK-blockade: according to study protocol (clinicaltrials.gov/ct2/show/NCT02967692). Adoptive $\mathrm{T}$ cell transfer was performed according to the study by Verdegaal et al. ${ }^{20}$

\section{Response data}

The best response achieved was assessed in the CDKN2A mutation carriers and compared with responses reported in the phase III clinical trials in patients with metastatic melanoma for ipilimumab, pembrolizumab, nivolumab and the ipilimumab/ nivolumab combination. ${ }^{12-15}$ By a binomial test it was evaluated if there was a statistically significant difference in the response rate in the carriers compared with an expected rate. The expected rate was calculated as a median of the responses in the clinical trials weighted against the numbers of carriers receiving each type of therapy (the $\mathrm{T}$ cell transfer and PD-1/BRAF/MEK therapies were assumed to have responses as high as for the ipilimumab/nivolumab combination).

\section{Mutational load analyses}

From publicly available data sets, as described in the study by Cirenajwis et al, ${ }^{21}$ melanomas with somatic CDKN2A mutation were analysed for association with tumour mutational load. In the tumours, total numbers of mutations found in 1461 frequently mutated cancer-associated genes were analysed. Non-parametrical Wilcoxon test was used to calculate the $\mathrm{p}$ value for difference in the total number of mutations with or without CDKN2A mutation. The $\mathrm{p}$ value was adjusted for study from which the tumours originated and for origin of tumours from primary melanomas or metastatic lesions. For linear regression, mutational load was log-transformed to approximate a normal distribution.

\section{RESULTS}

\section{Patients and immunotherapy response}

Among the 19 identified patients, nine different pathogenic germline mutations were found, most affecting both p16 and p14ARF (table 1). There were 10 men and 9 women and the median age when treatment started was 55 years (range 29-75 years). Fifteen of the 19 patients (79\%) had M1c-d disease which is a higher frequency compared with the patients that have been enrolled in the ipilimumab, pembrolizumab, nivolumab and ipilimumab/nivolumab trials $(71 \%, 64 \%, 61 \%$ and $58 \%$, respectively). Five of the patients $(26 \%)$ had brain metastasis (M1d according to the eighth AJCC staging system), such patients belong to a particularly poor prognosis group, and are usually not well represented in clinical trials (12\%, 10\%, 4\% and 4\% in the ipilimumab, pembrolizumab, nivolumab and ipilimumab/ nivolumab trials, respectively). Twelve of the patients (63\%) had received previous lines of treatments (the majority BRAF \pm MEK inhibitors) compared with $100 \%, 35 \%, 0 \%$ and $0 \%$ in the ipilimumab, pembrolizumab, nivolumab and ipilimumab/nivolumab trials, respectively. Activating mutations in the $B R A F$ gene were detected in the melanoma tumours of 14 patients (74\%).

Eight patients received CTLA-4 blockade, eight patients received PD-1 blockade, three patients received dual CTLA-4 and PD-1 blockade, one patient had adoptive T cell transfer therapy and one patient received triple combination of PD-1, BRAF and MEK inhibitors. Eleven of the 19 carriers (58\%) responded to immunotherapy compared with 10\%, 33\%, 43\% and 57\% of the patients in the ipilimumab, pembrolizumab, nivolumab and ipilimumab/nivolumab trials, respectively ${ }^{12-15}(p=0.03$, binomial test against an expected rate of 37\%). Further, 6 of the 19 carriers (32\%) had complete response, which is superior to what has been observed in any of the clinical trials where complete response was observed in $2 \%, 6 \%, 8 \%$ and $12 \%$ in the ipilimumab, pembrolizumab, nivolumab and ipilimumab/nivolumab trials, respectively $(p=0.01$, binomial test against an expected rate of 7\%). Treatment-related grade 3-4 side effects were observed in the carriers at frequencies comparable to what has been reported in clinical trials. The overall and progression-free survival in months for each of the patients is shown in table 1. Of the eight patients that received CTLA-4 inhibitors, six (75\%) were alive 1 year after the start of the treatment and five (63\%) were alive 2 years after treatment start. To compare, the 1-year and 2-year overall survival in the phase III ipilimumab study was $46 \%$ and $24 \%$, respectively. ${ }^{12}$ Among the carriers receiving PD-1 inhibitors or the CTLA-4/PD-1 inhibitor combination, a significant fraction of the patients had ongoing survival that was less than a year, and hence the 1-year and 2-year survival rates cannot be calculated for these therapies yet.

\section{Mutation burden of melanoma tumours}

Since total mutational and neoantigen load in tumours has been found to be a major predictive factor for the response to immunotherapies ${ }^{71617}$ we sought to investigate mutation burden in CDKN2A mutated tumours. For this purpose, we combined mutation data from 879 melanoma tumours from four publicly available studies. ${ }^{21}$ Majority of tumours were from metastatic lesions (82\%), while only $17 \%$ were from primary tumours. Of the 879 tumours, 118 were found to have deleterious CDKN2A mutations (figure $1 \mathrm{~A}$ ). Interestingly, the tumours with CDKN2A mutations had significantly higher total numbers of mutations in their genome compared with the tumours without CDKN2A mutation. (Wilcoxon test, $\mathrm{P}<0.001$, figure $1 \mathrm{~B}$ ). Further, the association between mutational load and CDKN2A mutation 


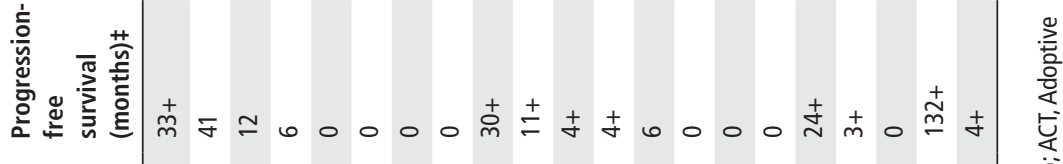

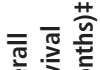

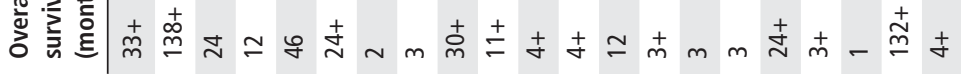

空

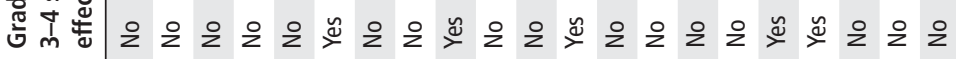

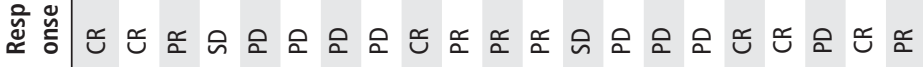

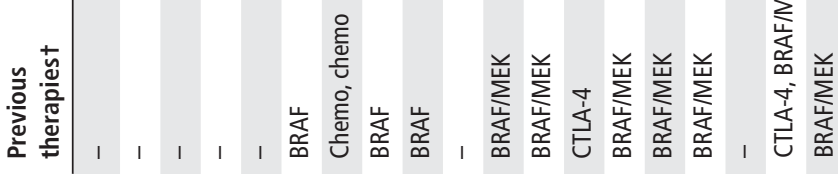

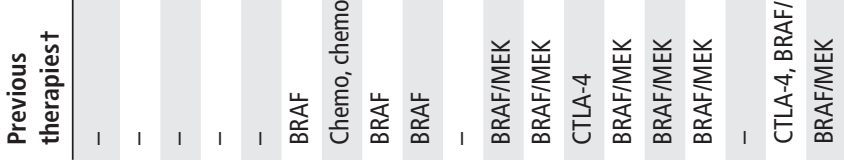

密蒂

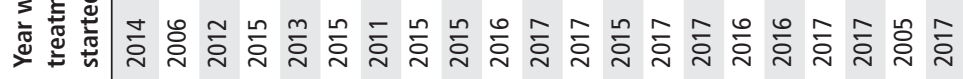

苍壱

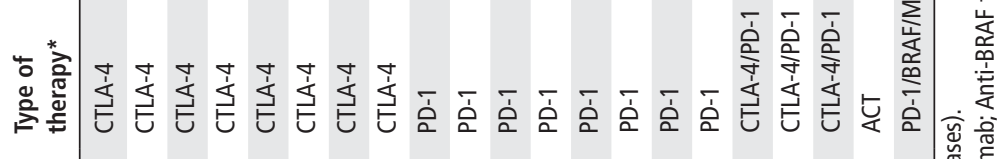

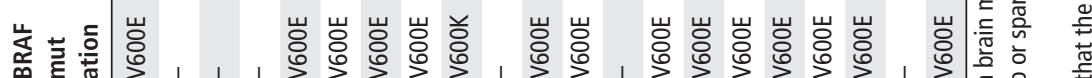

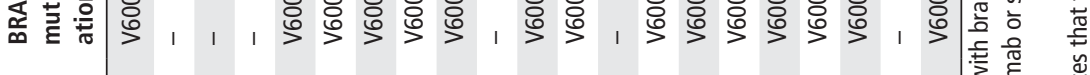

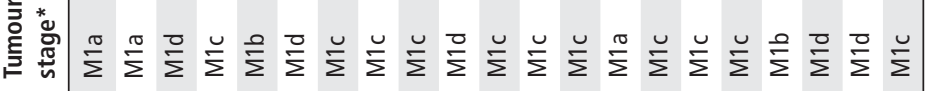

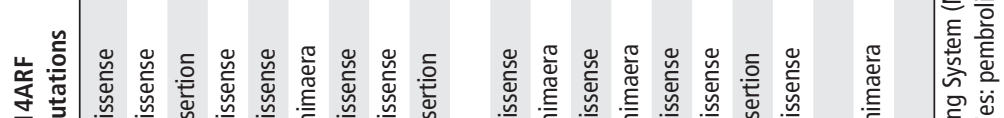

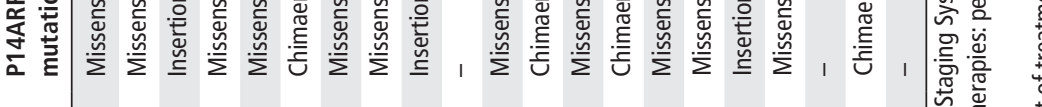

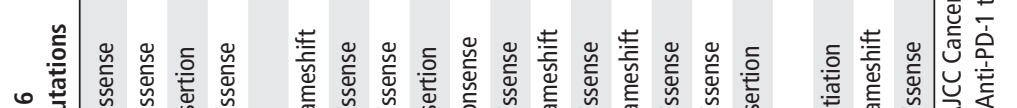

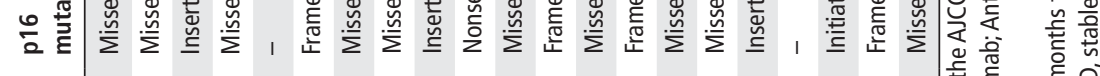

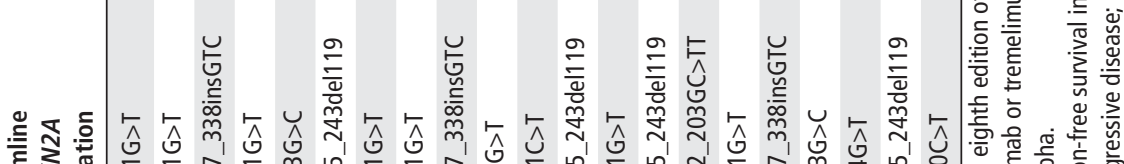

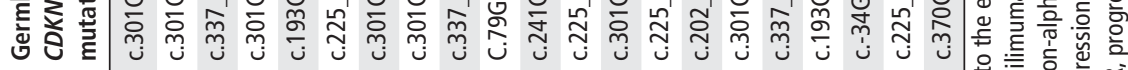

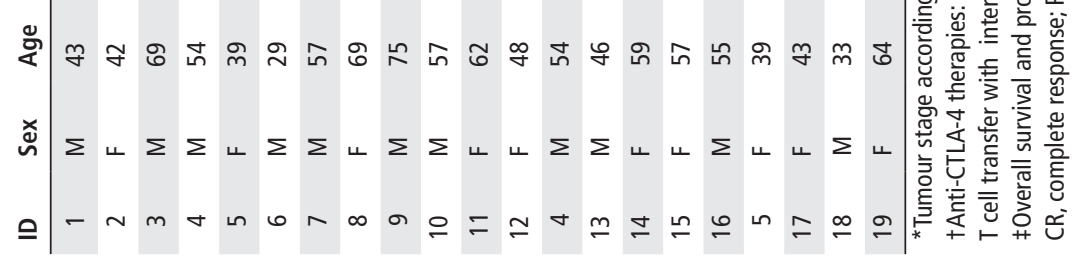




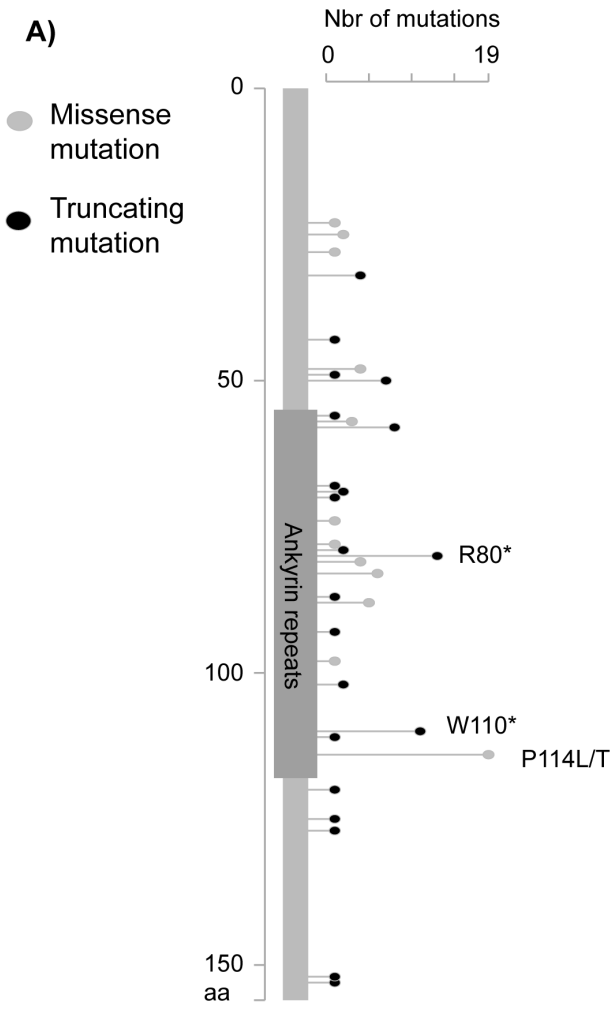

B)

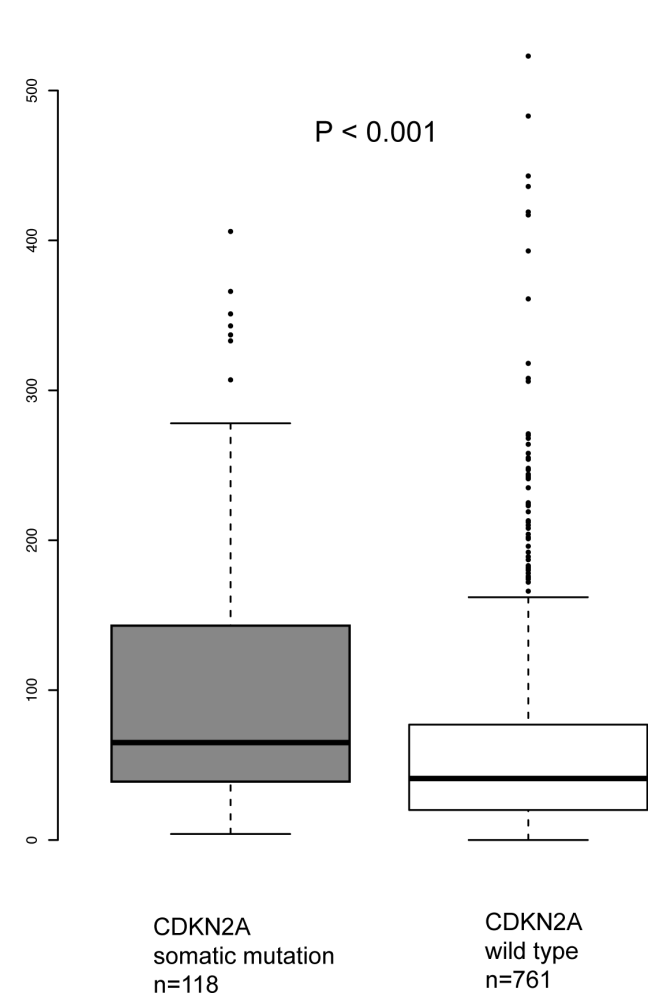

Figure 1 CDKN2A mutations and mutational load in melanoma tumours. (A) Distribution of somatic mutations in the CDKN2A gene created by the MutationMapper tool at cBioPortal. Highlighted are the three most frequently recurring mutations (P114L/T, R80* and W110*) observed in the melanoma tumours. (B) Mutational load analysis in 879 melanoma tumours, 118 tumours with CDKN2A mutations (mut) and 761 tumours without CDKN2A mutations (wt). The y axis shows total numbers of mutations found per tumour sample in 1461 frequently mutated cancer-associated genes. The non-parametrical Wilcoxon test was used to calculate the $p$ value. The association between mutational load and CDKN2A mutation status was confirmed in a linear regression model adjusted for study from which the tumours originated and for origin of tumours from primary melanomas or metastatic lesions, $\mathrm{p}<0.001$. For linear regression, mutational load was log-transformed to approximate a normal distribution.

status was confirmed in a linear regression model adjusted for study from which the tumours originated and for origin of tumours from primary melanomas or metastatic lesions, $\mathrm{P}<0.001$. No significant differences were found in the mutation load depending on if tumours had mutations in BRAF or NRAS (data not shown).

\section{CONCLUSIONS}

From this collaborative effort between oncogenic clinics in Sweden, Italy, The Netherlands, Spain and Australia we report of 19 CDKN2A mutation carriers with metastatic melanoma that have received novel immunotherapy treatments. Although a substantially higher frequency of the patients with CDKN2A mutated melanoma had M1c-M1d disease and/or were previously treated, they had responses to the immunotherapy regimens that were superior to what has been reported in clinical trials. $^{12-15}$ This was an unexpected finding and the underlying mechanisms for the responsiveness to immunotherapy among the carriers are uncertain. However, we explored a possible aetiology by analysing the mutation burden of somatic CDKN2A mutated tumours. Interestingly an increased number of genomic mutations was observed in melanomas with somatic CDKN2A mutation. Since cell cycle checkpoint controls are tightly associated with DNA damage response and repair mechanisms it is possible that CDKN2A mutated cells accumulate an increased number of mutations. Patients with CDKN2A mutated melanoma may therefore have improved immunotherapy responses due to increased tumour mutational load, resulting in more neoantigens and stronger antitumorous immune responses. However, such an association would optimally be explored by relating the mutation burden of tumours from CDKN2A mutation carriers to immunotherapy responses, however, the low number of carriers is a limiting factor for such analyses. Further studies are needed on the association between CDKN2A mutations, mutation load and immunotherapy responses and on underlying mechanisms for such associations.

The relatively low number of the carriers needs to be perceived in the light of the low population frequency of the CDKN $2 A$ mutation and while the majority of carriers develop melanoma, most known carriers are under surveillance to endorse prevention and early detection, with the result that relatively few have developed metastatic melanoma in our familial melanoma clinics in the past few years, during which the checkpoint inhibitors have been available.

PD-1 inhibitors have recently been found very effective, also in the adjuvant situation, that is, to prevent recurrence in patients operated for high-risk cutaneous melanomas. This is reassuring for CDKN2A mutation carriers that often develop multiple primary melanomas during their life spans. Further, the CTLA-4 and PD-1 inhibitors were first approved for treatment of disseminated melanoma, but later PD-1 blockade has also been approved for the treatment of other cancers including oropharyngeal and lung cancers although the response rates are inferior to what has been observed in melanoma. CDKN2A mutation carriers have significantly increased risks for lung and oropharyngeal cancers ${ }^{13}$ but we have yet not identified any 
CDKN2A mutation carrier that has received PD-1 blockade for such cancers. Considering the responses among the patients with melanoma it is possible that carriers affected by lung and oropharyngeal cancers would respond well to such immunotherapies.

In familial melanoma clinics, CDKN2A mutation carriers are frequently encountered and here knowledge on risk factors, outcomes and treatments is invaluable. The CDKN2A mutation carriers in the study had a good response rate to the novel immunotherapy regimens, which we believe is helpful information for caregivers that manage CDKN2A mutation carriers and their families. Based on our findings, CDKN2A mutation predicts a good response to immunotherapies, possibly due to increased mutational load in CDKN2A mutated tumours. Further, in the light of the previous publication on poor melanoma-specific survival in the CDKN2A mutation carriers (carried out in the 'pre-checkpoint inhibitor era'), ${ }^{1}$ these findings are reassuring for this group of patients.

\section{Author affiliations}

'Department of Oncology Pathology, Karolinska Institutet and Karolinska University Hospital Solna, Stockholm, Sweden

${ }^{2}$ Department of Internal Medicine and Medical Specialties, University of Genoa and Genetics of Rare Cancers, IRCCS Ospedale Policlinico San Martino, Genoa, Italy ${ }^{3}$ Department of Dermatology, LUMC, Leiden, The Netherlands

${ }^{4}$ Melanoma Unit, Dermatology Department, Hospital Clinic de Barcelona, Institut d'Investigacions Biomèdiques Auqust Pi i Sunyer (IDIBAPS), Universitat de Barcelona, Barcelona, Spain

${ }^{5}$ Centro de Investigación Biomédica en Red (CIBER) de Enfermedades Raras, Instituto de Salud Carlos III, Barcelona, Spain

${ }^{6}$ Department of Oncology, The Sahlgrenska Academy, University of Gothenburg, Göteborg, Sweden

Department of Clinical Medicine, Westmead Hospital and Macquarie University, Sydney, New South Wales, Australia

${ }^{8}$ Department of Oncology, Clinical Sciences Lund, Lund University and Skåne University Hospital, Lund, Sweden.

${ }^{9}$ Department of Medical Oncology, IRCCS Ospedale Policlinico San Martino, Genoa, Italy

${ }^{10}$ Department of Medical Oncology, Leiden University Medical Center, Leiden, The Netherlands

Contributors All authors (HH, PG, RvD, SP, ML, RK, ML, PQ, LP, EK, MP, CC, HO, $\mathrm{VH}, \mathrm{GJ})$ contributed to the accrual of subjects and data. Conception of the work and drafting of the manuscript was done by $H H$ and GJ. All authors $(H H, P G, R v D, S P$, $M L, R K, M L, P Q, L P, E K, M P, C C, H O, V H, G J)$ were involved in the data analysis and interpretation, critical revision of the article and final approval of the version to be published.

Funding This work was supported by grants from The Castenbäck foundation, The Swedish Cancer Society (CAN 2017/503), the Swedish Society for Medical research (SSMF), the Swedish Research Council, Swedish governmental funding for healthcare research (ALF), the Dutch Cancer Society (UL2012-5489), the Italian Association for Cancer Research (AIRC -IG15140 and 21073), the Italian Ministry of Health grant FR-201602362288, the Spanish Fondo de Investigaciones Sanitarias grants (PI15/00716, PI15/00956) and Instituto de Salud Carlos III and the European Development Regional Fund (ERDF).

Competing interests None declared.

Patient consent Not required.

Ethics approval The Ethical Review Board in Stockholm, Sweden; The Ethical Review Board in Genoa, Italy; The Ethical Review Board in Leiden, Netherlands; The Ethical Review Board in Barcelona, Spain; The Ethical Review Board in Sydney, Australia.

Provenance and peer review Not commissioned; externally peer reviewed.

Data sharing statement There are no additional data related to this study that the authors think would be helpful for other reasearchers.

Open access This is an open access article distributed in accordance with the Creative Commons Attribution Non Commercial (CC BY-NC 4.0) license, which permits others to distribute, remix, adapt, build upon this work non-commercially, and license their derivative works on different terms, provided the original work is properly cited, appropriate credit is given, any changes made indicated, and the use is non-commercial. See: http://creativecommons.org/licenses/by-nc/4.0/.

\section{REFERENCES}

1. Helgadottir $\mathrm{H}$, Höiom V, Jönsson $\mathrm{G}$, Tuominen $\mathrm{R}$, Ingvar $\mathrm{C}$, Borg $\mathrm{A}$, Olsson $\mathrm{H}$, Hansson J. High risk of tobacco-related cancers in CDKN2A mutation-positive melanoma families. J Med Genet 2014:51:545-52

2. Harland M, Cust AE, Badenas C, Chang YM, Holland EA, Aguilera P, Aitken JF, Armstrong BK, Barrett JH, Carrera C, Chan M, Gascoyne J, Giles GG, Agha-Hamilton C, Hopper JL, Jenkins MA, Kanetsky PA, Kefford RF, Kolm I, Lowery J, Malvehy J, Ogbah Z, Puig-Butille JA, Orihuela-Segalés J, Randerson-Moor JA, Schmid H, Taylor CF, Whitaker L, Bishop DT, Mann GJ, Newton-Bishop JA, Puig S. Prevalence and predictors of germline CDKN2A mutations for melanoma cases from Australia, Spain and the United Kingdom. Hered Cancer Clin Pract 2014;12:20.

3. Potjer TP, Helgadottir H, Leenheer M, van der Stoep N, Gruis NA, Hoiom V, Olsson H, van Doorn R, Vasen HFA, van Asperen CJ, Dekkers OM, Hes FJ. Dutch Working Group for Clinical O. CM-Score: a validated scoring system to predict CDKN2A germline mutations in melanoma families from Northern Europe. J Med Genet 2018.

4. Puig S, Malvehy J, Badenas C, Ruiz A, Jimenez D, Cuellar F, Azon A, Gonzàlez U, Castel T, Campoy A, Herrero J, Martí R, Brunet-Vidal J, Milà M. Role of the CDKN2A locus in patients with multiple primary melanomas. J Clin Oncol 2005;23:3043-51.

5. Helgadottir $H$, Höiom V, Tuominen R, Nielsen K, Jönsson G, Olsson H, Hansson J. Germline CDKN2A Mutation Status and Survival in Familial Melanoma Cases. s. J Nat Cancer Inst 2016;108:djw135.

6. Hodis E, Watson IR, Kryukov GV, Arold ST, Imielinski M, Theurillat JP, Nickerson E, Auclair D, Li L, Place C, Dicara D, Ramos AH, Lawrence MS, Cibulskis K, Sivachenko A, Voet D, Saksena G, Stransky N, Onofrio RC, Winckler W, Ardlie K, Wagle N, Wargo J, Chong K, Morton DL, Stemke-Hale K, Chen G, Noble M, Meyerson M, Ladbury JE, Davies MA, Gershenwald JE, Wagner SN, Hoon DS, Schadendorf D, Lander ES, Gabriel $\mathrm{SB}$, Getz G, Garraway LA, Chin L. A landscape of driver mutations in melanoma. Cell 2012:150:251-63.

7. Lauss M, Donia M, Harbst K, Andersen R, Mitra S, Rosengren F, Salim M, VallonChristersson J, Törngren T, Kvist A, Ringnér M, Svane IM, Jönsson G. Mutational and putative neoantigen load predict clinical benefit of adoptive T cell therapy in melanoma. Nat Commun 2017:8:1738.

8. Grafström E, Egyházi S, Ringborg U, Hansson J, Platz A. Biallelic deletions in INK4 in cutaneous melanoma are common and associated with decreased survival. Clin Cancer Res 2005:11:2991-7.

9. Straume 0 , Sviland L, Akslen LA. Loss of nuclear p16 protein expression correlates with increased tumor cell proliferation (Ki-67) and poor prognosis in patients with vertical growth phase melanoma. Clin Cancer Res 2000;6:1845-53.

10. Puig S, Castro J, Ventura PJ, Ruiz A, Ascaso C, Malvehy J, Estivill X, Mascaro JM, Lecha $\mathrm{M}$, Castel T. Large deletions of chromosome $9 p$ in cutaneous malignant melanoma identify patients with a high risk of developing metastases. Hospital Clinic Malignant Melanoma Group, University of Barcelona. Melanoma Res 2000;10:231-6.

11. Alexandrov $L B$, Nik-Zainal $S$, Wedge $D C$, Aparicio $S A$, Behjati $S$, Biankin $A V$, Bignell GR, Bolli N, Borg A, Borresen-Dale AL, Boyault S, Burkhardt B, Butler AP, Caldas C Davies HR, Desmedt C, Eils R, Eyfjord JE, Foekens JA, Greaves M, Hosoda F, Hutter B, llicic T, Imbeaud S, Imielinsk M, Jager N, Jones DT, Jones D, Knappskog S, Kool M, Lakhani SR, Lopez-Otin C, Martin S, Munshi NC, Nakamura H, Northcott PA, Pajic M, Papaemmanuil E, Paradiso A, Pearson JV, Puente XS, Raine K, Ramakrishna M, Richardson AL, Richter J, Rosenstiel P, Schlesner M, Schumacher TN, Span PN, Teague JW, Totoki Y, Tutt AN, Valdes-Mas R, van Buuren MM, van 't Veer L, Vincent-Salomon A, Waddell N, Yates LR. Australian Pancreatic Cancer Genome I, Consortium IBC, Consortium IM-S, PedBrain I, Zucman-Rossi J, Futreal PA, McDermott U, Lichter P Meyerson M, Grimmond SM, Siebert R, Campo E, Shibata T, Pfister SM, Campbell PJ, Stratton MR. Signatures of mutational processes in human cancer. Nature 2013:500:415-21.

12. Hodi FS, O'Day SJ, McDermott DF, Weber RW, Sosman JA, Haanen JB, Gonzalez R, Robert C, Schadendorf D, Hassel JC, Akerley W, van den Eertwegh AJ, Lutzky J, Lorigan P, Vaubel JM, Linette GP, Hogg D, Ottensmeier CH, Lebbé C, Peschel C, Quirt I, Clark JI, Wolchok JD, Weber JS, Tian J, Yellin MJ, Nichol GM, Hoos A, Urba WJ. Improved survival with ipilimumab in patients with metastatic melanoma. N Eng/ I Med 2010;363:711-23.

13. Robert C, Long GV, Brady B, Dutriaux C, Maio M, Mortier L, Hassel JC, Rutkowski P, McNeil C, Kalinka-Warzocha E, Savage KJ, Hernberg MM, Lebbé C, Charles J, Mihalcioiu C, Chiarion-Sileni V, Mauch C, Cognetti F, Arance A, Schmidt H, Schadendorf D, Gogas H, Lundgren-Eriksson L, Horak C, Sharkey B, Waxman IM, Atkinson $\mathrm{V}$, Ascierto PA. Nivolumab in previously untreated melanoma without BRAF mutation. N Engl J Med 2015;372:320-30.

14. Robert C, Schachter J, Long GV, Arance A, Grob JJ, Mortier L, Daud A, Carlino MS, McNeil C, Lotem M, Larkin J, Lorigan P, Neyns B, Blank CU, Hamid O, Mateus C, Shapira-Frommer R, Kosh M, Zhou H, Ibrahim N, Ebbinghaus S, Ribas A. KEYNOTE-006 investigators. Pembrolizumab versus Ipilimumab in Advanced Melanoma. N Engl J Med 2015;372:2521-32.

15. Larkin J, Chiarion-Sileni V, Gonzalez R, Grob JJ, Cowey CL, Lao CD, Schadendorf D, Dummer R, Smylie M, Rutkowski P, Ferrucci PF, Hill A, Wagstaff J, Carlino MS, Haanen 
JB, Maio M, Marquez-Rodas I, McArthur GA, Ascierto PA, Long GV, Callahan MK, Postow MA, Grossmann K, Sznol M, Dreno B, Bastholt L, Yang A, Rollin LM, Horak C, Hodi FS, Wolchok JD. Combined Nivolumab and Ipilimumab or Monotherapy in Untreated Melanoma. N Engl J Med 2015;373:23-34.

16. Hugo W, Zaretsky JM, Sun L, Song C, Moreno BH, Hu-Lieskovan S, Berent-Maoz B, Pang J, Chmielowski B, Cherry G, Seja E, Lomeli S, Kong X, Kelley MC, Sosman JA, Johnson DB, Ribas A, Lo RS, Rs L. Genomic and Transcriptomic Features of Response to Anti-PD-1 Therapy in Metastatic Melanoma. Cell 2016;165:35-44.

17. McGranahan N, Furness AJ, Rosenthal R, Ramskov S, Lyngaa R, Saini SK, JamalHanjani M, Wilson GA, Birkbak NJ, Hiley CT, Watkins TB, Shafi S, Murugaesu N, Mitter R, Akarca AU, Linares J, Marafioti T, Henry JY, Van Allen EM, Miao D, Schilling B, Schadendorf D, Garraway LA, Makarov V, Rizvi NA, Snyder A, Hellmann MD, Merghoub T, Wolchok JD, Shukla SA, Wu CJ, Peggs KS, Chan TA, Hadrup SR, Quezada $S A$, Swanton C. Clonal neoantigens elicit T cell immunoreactivity and sensitivity to immune checkpoint blockade. Science 2016;351:1463-9.

18. Snyder A, Makarov V, Merghoub T, Yuan J, Zaretsky JM, Desrichard A, Walsh LA, Postow MA, Wong P, Ho TS, Hollmann TJ, Bruggeman C, Kannan K, Li Y, Elipenahli C,
Liu C, Harbison CT, Wang L, Ribas A, Wolchok JD, Chan TA. Genetic basis for clinical response to CTLA-4 blockade in melanoma. N Engl J Med 2014;371:2189-99.

19. Bruno W, Ghiorzo P, Battistuzzi L, Ascierto PA, Barile M, Gargiulo S, Gensini F, Gliori S, Guida M, Lombardo M, Manoukian S, Menin C, Nasti S, Origone P, Pasini B, Pastorino L, Peissel B, Pizzichetta MA, Queirolo P, Rodolfo M, Romanini A, Scaini MC, Testori A, Tibiletti MG, Turchetti D, Leachman SA, Bianchi Scarrà G, Imi I; IMI, Italian Melanoma Intergroup. Clinical genetic testing for familial melanoma in Italy: a cooperative study. J Am Acad Dermatol 2009;61:775-82.

20. Verdegaal EM, Visser M, Ramwadhdoebé $T H$, van der Minne CE, van Steijn JA, Kapiteijn E, Haanen JB, van der Burg SH, Nortier JW, Osanto S. Successful treatment of metastatic melanoma by adoptive transfer of blood-derived polyclonal tumor-specific CD4+ and CD8+ T cells in combination with low-dose interferon-alpha. Cancer Immunol Immunother 2011;60:953-63.

21. Cirenajwis $H$, Lauss M, Ekedahl H, Törngren T, Kvist A, Saal LH, Olsson H, Staaf J, Carneiro A, Ingvar C, Harbst K, Hayward NK, Jönsson G. NF1-mutated melanoma tumors harbor distinct clinical and biological characteristics. Mol Oncol 2017;11:438-51. 